\title{
Transposition of the Great Arteries. Evaluation of the Results and Current Management
}

\author{
Edmar A tik
}

São Paulo, SP - Brazil

The analysis of the surgical risk as well as the risk at mid- and long-term follow-up of the predominant techniques used to correct transposition of the great vessels allow us to objectify a preference for anatomical correction using the Jatene surgical procedure at this time ${ }^{1}$.

Operative risk for this surgery has become similar to the 2 to $5 \%$ risk ${ }^{2-6}$ observed for corrections at the atrial level, although some centers still have risks higher than $10 \%$ or even $20 \%^{7}$.

Mid-term results up to five years show a 5\% risk $^{2-6,8-16}$, ranging from 0 to $10 \%$, and relate to coronary events in the anatomical correction ${ }^{2-6}$ and to venous stenosis, ventricular failure, and tricuspid insufficiency when the correction is performed at the atrial level ${ }^{8-16}$.

At long-term follow-up (10 to 20 years or even more), significant contrast can be observed in survival between the two types of surgery, with surgeries involving an atrial switch showing a 20 to $40 \%$ risk of death due to arrhythmias and ventricular failure, ${ }^{9-16}$ and with surgeries involving the arterial switch showing 1 to $2 \%$ risk due to the new aortic valve regurgitation ${ }^{2-7}$. It is easy to understand that these numbers clearly favor the indication of the anatomical correction with the Jatene procedure.

Aiming to establish this trend with even more certainty, it is important to analyze the quality and the main characteristics of its outcome. To do that, it is important to consider that the postoperative follow-up for any congenital heart disease depends on three variables: the anatomo-functional situation before surgery, the technique used, and any postoperative complications. Early correction, which seems mandatory nowadays, aims to avoid any acquired secondary abnormalities that can jeopardize the surgical results at long-term follow-up, even in the presence of the recently observed technical progress. Thus, at present, postoperative results seem to be related more and more to the last two variables.

However, some problems, such as cardiac dilation and hypertrophy and ventricular failure, among others, continue to interfere with the patient's outcome and to challenge

Instituto do Coração do Hospital das Clínicas - FMUSP

Mailing address: Edmar Atik - InCor - Av. Dr. Enéas C. Aguiar, 44 - 05403-000 São Paulo, SP - Brazil - e-mail: conatik@incor.usp.br the present management. Therefore, these complications need to be analyzed separately for the two techniques.

The degree and duration of hypoxemia, right and left ventricular function, pulmonary hypertension, and the type of associated congenital heart disease (especially atrial and ventricular septal defects) are some of the problems that occur when the functional correction is performed at the atrial level.

Complications of the surgery that can be associated with the anatomo-functional conditions of the disease are supraventricular arrhythmias, right ventricular failure, tricuspid regurgitation, and stenosis of either the pulmonary or the systemic venous systems or both of these ${ }^{8-16}$.

Taking all these facts into consideration, postoperative outcome certainly depends on the time surgery is performed; if early (three to six months), no acquired complications should be expected. However, if surgery is performed later on, several factors can interfere with the postoperative outcome.

Anatomo-pathologic studies in patients with transposition of the great arteries and atrial septal defect who die at different ages show that pulmonary vascular disease (Heath-Edwards histhological classification greater than grade III), when the patient was operated upon after the first year of life, had a $34 \%$ incidence, which was twice as high as the $17 \%$ incidence observed in patients operated upon at 3 to 12 months of age ${ }^{8}$.

The experience at the Hospital for Sick Children in Toronto, Canada, with the Mustard technique shows that the outcome in patients with transposition of the great arteries with ventricular septal defect is less favorable than that in patients with an atrial septal defect, even at a mid-term follow-up of five years: $89 \%$ of patients with an atrial septal defect survive, but survival in those with a ventricular septal defect is $54 \%{ }^{8}$. Long-term follow-up of 20 or 30 years shows an $80 \%$ survival in patients with an atrial septal defect, according to the same group ${ }^{9}$.

Others have shown 64 to $90 \%$ survival in up to 28 years of follow-up after the Mustard surgery ${ }^{10-14}$. Here too, less favorable results were observed in patients with associated ventricular septal defect ${ }^{11}$ (table I). During this longterm follow-up period, prevalence of supraventricular arrhythmias is high, occurring in from 20 to $82 \%$ of cases, according to the same authors ${ }^{10-14}$. Right ventricular failure was 
also detected in 4.7 to $10 \%$ of the cases and, together with supraventricular arrhythmias, it is responsible for complications in the long-term follow-up.

Long-term follow-up after the Senning technique (table II) has shown a better survival when compared with the Mustard technique, ranging from 78 to $90 \%{ }^{10,11,15,16}$. It is interesting to note that, in the largest international experience with the Seening technique, Genoni et al ${ }^{15}$ report similar mortality rates among patients with associated ventricular and atrial septal defects in Zurich, Switzerland. This is different from that reported for the other techniques of atrial switch. However, incidence of arrhythmias and ventricular dysfunction are similar for the two procedures (tables II and III).

In our surgical experience at InCor (Instituto do Coração of the Medical School of the University of São Paulo, Brazil), although the Senning procedure has been evaluated in only $14 \%$ of the patients who had been operated upon from 1978 to 1995 , the results were similar to those described in the literature. Among 52 patients who were re-evaluated at long-term follow-up, ranging from 10 to 19 years after surgery, the incidence of arrhythmias was $86 \%$ (45 patients), characterized by supraventricular premature beats in 11 , ventricular premature beats in 9 , supra- and ventricular premature beats in 6 , junctional rhythm in 7 , and atrial flutter in 2. A ventricular pacemaker was implanted in $9(17.3 \%)$. Moderate tricuspid regurgitation occurred in 16 $(30.7 \%)$, and mild tricuspid regurgitation occurred in 4 (7.6\%). Tricuspid regurgitation was noted to correlate with ventricular failure as analyzed by radioisotopic ventriculography.

\begin{tabular}{|c|c|c|c|c|}
\hline \multicolumn{5}{|c|}{$\begin{array}{l}\text { Table I - Evaluation of the } 10 \text { to 28-year follow-up in patients after } \\
\text { the Mustard operation }\end{array}$} \\
\hline Author/year & Number & $\begin{array}{c}\text { Survival } \\
\%\end{array}$ & $\begin{array}{l}\text { Arrhythmia } \\
\%\end{array}$ & $\begin{array}{l}\text { Right ventric. } \\
\text { failure }\end{array}$ \\
\hline Shinoka-93 & 63 & 64 & 20 & $4.7 \%$ \\
\hline Helbing-94 & 60 & $\begin{array}{c}\text { ASD } 90 \\
\text { VSD60 }\end{array}$ & 82 & 6.6 \\
\hline Meijboom-96 & 91 & 75 & 41 & \\
\hline Wilson-98 & 113 & 80 & 5 & \\
\hline Puley-99 & 86 & 70 & 66 & 10 \\
\hline
\end{tabular}

\begin{tabular}{|c|c|c|c|c|}
\hline \multicolumn{5}{|c|}{$\begin{array}{l}\text { Table II - Evaluation of the } 10 \text { to } 31 \text {-year follow-up after the } \\
\text { Senning surgery }\end{array}$} \\
\hline Author/year & Number & $\begin{array}{c}\text { Survival } \\
\%\end{array}$ & $\begin{array}{c}\text { Arrhythmias } \\
\%\end{array}$ & $\begin{array}{l}\text { Right ventr. } \\
\text { failure }\end{array}$ \\
\hline Shinoka-93 & 74 & 90 & 8 & $2.7 \%$ \\
\hline Helbing-94 & 62 & 78 & 47 & 6.4 \\
\hline \multirow[t]{2}{*}{ Genoni-96 } & 165 & ASD 83 & & 5 \\
\hline & 177 & VSD 81 & & 5 \\
\hline \multirow[t]{2}{*}{ Kirjavainen-99 } & 73 & ASD 90 & 66 & \\
\hline & 27 & VSD 78 & 93 & \\
\hline
\end{tabular}

Several pre-existing anatomo-functional factors, such as the intensity and duration of hypoxemia, pulmonary hypertension, ventricular dysfunction, a dilated pulmonary artery, associated defects (especially coarctation of the aorta and ventricular septal defect), and previous operation, such as pulmonary artery banding, influence the long-term follow-up when the Jatene procedure is performed.

Complications from these pre-existing factors or resulting from the technique itself are mainly represented by ventricular failure, coronary events, right ventricular outflow tract obstruction, and regurgitation of the new aortic valve $^{2-7}$.

Age at the time of surgery, in addition to all these factors, surely influences the possibility of progression of pulmonary hypertension, with $25 \%$ of the patients operated upon at 3 to 12 months showing Heath Edwards grade III and higher, and $78 \%$ of the patients who underwent surgery after the first year of life show this degree of pulmonary vasculature abnormalities ${ }^{8}$.

Mid-term follow-up is greatly influenced by coronary events after the Jatene procedure, as demonstrated in several studies (table III), where coronaryangiographies show them to occur in 3 to $11 \%$ of the cases during a 5-year follow-up after the surgery, with a mortality rate ranging from 0 to $10 \%{ }^{2-6}$.

At a longer follow-up, other complications derived from the Jatene surgery may occur, which are not necessarily hazardous in the evolution, because the incidence of pulmonary stenosis has decreased and the degree of aortic regurgitation is usually mild or even absent. It is estimated that only $5 \%$ of the cases of aortic regurgitation at longterm follow-up are significant enough to interfere with the cardiovascular dynamics ${ }^{7}$.

The experience derived from the first cases operated upon at the Dante Pazzaneze Cardiology Institute in São Paulo, Brazil, where the Jatene procedure was developed by Jatene et al. in $1975^{1}$, together with the first cases performed at InCor up to 1987, the long-term follow-up was established in another study by Jatene et al ${ }^{7}$.

In 116 cases, in spite of the presence of untoward preoperative anatomo-functional factors, aggravated by an older age at the time of surgery, of the predominance of associated ventricular septal defects and of the fact that it was an initial experience, late follow-up was considered adequate, because $89 \%$ of the 73 survivors were in functional class I.

\begin{tabular}{|lccc|}
\hline $\begin{array}{c}\text { Table III - Coronary events evaluated by coronaryangiography at } \\
\text { mid-term follow-up after the Jatene operation. }\end{array}$ \\
\hline Author/year & Number & $\begin{array}{c}\text { Coronary } \\
\text { abnormality }\end{array}$ & Mortality \\
\hline Tsuda-92 & 59 & $6-10 \%$ & $6-100 \%$ \\
Tanel-95 & 366 & $13-3$ & $7-7$ \\
Bounet-96 & 58 & $5-8.6$ & - \\
Bonhoeffer-97 & 165 & $12-7.2$ & $11-42$ \\
Tamisier-97 & 236 & $26-11$ & \\
\hline ASD- atrial septal defect; VSD- ventricular septal defect. \\
\hline
\end{tabular}


The late mortality rate is $4.3 \%$ and is related to coronary events (sudden death) in 3\% and to infectious endocarditis in $1.3 \%$ of the cases. Pulmonary stenosis with an incidence of $11 \%$ and aortic insufficiency with $4 \%$ did not intefere with a favorable outcome ${ }^{7}$.

Data from the literature show that patients' outcome is better in the absence of complicating factors and when surgery is performed ideally in the first days of life on a baby with adequate weight for the age above $3,400 \mathrm{~g}$, with normal contralateral origin of the coronary arteries, in the absence of hypoxia and in a center with a large experience with the switch operation.

In summary, long-term follow-up is more favorable when patients with transposition of the great arteries undergo the Jatene operation instead of the atrial switch; patients who undergo the former procedure have a better exercise capacity, are more often in functional class I of the NYHA, have no supraventricular arrhythmias, and have better ventricular function. Other factors, such as pulmonary stenosis and aortic insufficiency, although more frequent, are not responsible for hemodynamic compromise.

Therefore, efforts should be made to perform the Jatene surgery when managing patients with transposition of the great vessels, which can be done primarily or after "preparing the left ventricle".

More accurate and less harmful techniques are a big challenge in pediatric cardiology, now that early surgery has already been established as essential for avoiding acquired factors that could lead to an unfavorable anatomofunctional pre-operative situation.

\section{References}

1. Jatene AD, Fontes VF, Paulista PP, et al. Anatomic correction of transposition of the great vessels. J Thorac Cardiovasc Surg 1976; 72: 364-70.

2. Tsuda E, Imakita M, Yagihara T, et al. Late death after arterial switch operation for transposition of the great arteries. Am Heart J 1992; 124: 1551-7.

3. Tanel RE, Wernovsky G, Landzberg MJ, Perry SB, Burke RP. Coronary artery abnormalities detected at cardiac catheterization following the arterial switch operation for transposition of the great arteries. Am J Cardiol 1995; 76: 153-7.

4. Bonnet D, Bonhoeffer P, Piechaud JF, et al. Long-term fate of the coronary arteries after the arterial switch operation in newborns with transposition of the great arteries. Heart 1996; 76: 274-9.

5. Bonhoeffer P, Bonnet D, Piechaud JF, et al. Coronary artery obstruction after the arterial switch operation for transposition of the great arteries in newborns. J Am Coll Cardiol 1997; 29: 202-6.

6. Tamisier D, Ouaknine R, Pouard P, et al. Neonatal arterial switch operation: coronary artery patterns and coronary events. Eur J Cardiothorac Surg 1997; 11: 8107.

7. Jatene FB, Bosisio IBJ, Jatene MB, Souza LCB, Barbero-Marcial M, Jatene AD Late results (50 to 182 months) of the Jatene operation. Eur J Cardiothorac Surg 1992; 6: 575-8.

8. Williams WG, Turley K, Blackstone EH, Kirklin JW. A comparison of early and intermediate term survival after atrial switch operation for transposition. Personal communication; 1992. Apud Kirklin JW, Barratt-Boyes G. Cardiac Surgery, $2^{\text {nd }}$ edition. New York: Churchill Livingstone, 1993: 1443.
9. Williams WG, Trusler GA, Kirklin JW, et al. Early and late results of a protocol for simple transposition leading to an atrial switch (Mustard) repair. J Thorac Cardiovasc Surg 1988; 95: 717-22

10. Shinoka T. Late results and problems after atrial switch operation. Nippon Kyobu Geka Gakkai Zasshi 1993; 41: 1298-306.

11. Helbing WA, Hansen B, Ottemkamp J, Chin JG, Brom AG, Quaegebeur JM. Long-term results of atrial correction for transposition of the great arteries. Comparison of Mustard and Senning operations. J Thorac Cardiovasc Surg 1994; 108: 363-72.

12. Meijboom F, Szatmari A, Deckers JW, et al. Long-term follow-up (10 to 17 years) after Mustard repair for transposition of the great arteries. J Thorac Cardiovasc Surg 1996; 111: 1158-68.

13. Wilson NJ, Clarkson PM, Barratt-Boyes BG, et al. Long-term outcome after the Mustard repair for simple transposition of the great arteries. 28-year follow-up. J Am Coll Cardiol 1998; 32: 758-65.

14. Puley G, Siu S, Connelly M, et al. Arrhythmia and survival in patients $>18$ years of age after the Mustard procedure for complete transposition of the great arteries. Am J Cardiol 1999; 83: 1080-4.

15. Genoni M, von Segesser L, Wilhelm M, Arbenz U, Turina M. 32 years of Senning's correction for transposition of the great vessels. Swiss Surg Suppl 1996; (suppl 1): 32-5.

16. Kirjavainen M, Happonen JM, Louhimo I. Late results of Senning operation. J Thorac Cardiovasc Surg 1999; 117: 488-95. 